\title{
Lima, rumbo al bicentenario
}

\author{
Entrevistas a Jorge Muñoz Wells, José de la Puente Brunke, Pedro Pablo \\ Alayza, Elena Benavides, José Quezada Macchiavello, César Guadalupe \\ Mendizábal, David Mutal Vermeulen y Enrique Bonilla Di Tolla
}

\author{
Ramiro Velaochaga Sacio \\ Universidad de Lima
}

\section{Jorge Muñoz Wells}

Abogado por la Pontificia Universidad Católica del Perú. Alcalde del distrito de Miraflores.

\section{Tomando en cuenta el pasado histórico y cultural de Lima, ¿cuáles considera que han sido los principales cambios urbanos en la ciudad?}

La ciudad de Lima ha atravesado por un proceso de crecimiento demográfico explosivo, debido a un importante fenómeno de migraciones internas que se dio, principalmente, entre 1940 y 1980; que englobó a la población de origen rural, llevándola hacia las principales ciudades del país. Esto generó una ocupación del suelo espontánea y, a la vez, informal, ocupaciones de terrenos que se dieron, muchas veces, en sectores no aptos para habitar.

Actualmente, este fenómeno migratorio ha disminuido con relación a décadas pasadas; sin embargo, y aunado a un crecimiento económico en el país, el desarrollo inmobiliario viene tomando un espacio importante en nuestra capital, tanto en el centro de la ciudad como en las zonas periféricas. Así, se han creado urbanizaciones formales y generado nuevos centros de desarrollo, como los conglomerados comerciales y empresariales, lo que ha hecho posible convertir a Lima y Callao en centros dinamizadores del país, así como potenciar su proyección al mundo sobre la cuenca del Pacífico; oportunidad que también comparte con el distrito de Miraflores.

No obstante, este crecimiento ha generado problemas de conectividad entre los centros de desarrollo y los servicios económicos y culturales que se ofrecen en Lima, debido a la falta de planificación y orden en la ciudad.

2. ¿Cuáles considera que son los problemas más resaltantes en los cambios señalados?

Uno de los principales problemas urbanos es el transporte. Como sistema capaz de articular y unir toda la ciudad, el transporte debe ser pensado a partir de la compleja realidad metropolitana en la que presta su servicio y las diversas condiciones de la demanda en los distintos grupos de la población. Además, debe ser accesible y de alta calidad para todos, debe integrarse a otras redes de movilidad, y respetar un plan de movilidad metropolitana que contenga una jerarquía modal de movilidad. 
En ese sentido, el gobierno metropolitano debe promover el referido plan teniendo en cuenta que, en la jerarquía modal, el peatón es primero; también, articular los diferentes medios de transporte y fomentar una movilidad sostenible.

Desde el 2011, en Miraflores venimos trabajando el Plan Integral de Ordenamiento Vial (PIOV), que busca convertir al distrito en un lugar que promueva la movilidad sostenible y priorice al peatón, tal como ocurre en Bogotá, Medellín, Barcelona, entre otras ciudades. Así, fomentamos que la gente camine. De igual modo, venimos implementando una red pública de bicicletas, además de promover el uso del transporte público.

Asimismo, aplicamos una serie de medidas, como la implementación de la Central de Monitoreo de Tránsito, que será la más moderna del país, iniciativa que busca hacer más eficiente el flujo del transporte en el distrito. Esta central administrará, en tiempo real y desde la misma sede, los controladores semafóricos, según la carga vehicular. A este control también se integrarán los datos alcanzados por el aplicativo Waze, con lo que se optimizará la cobertura de los inspectores municipales de tránsito.

\section{3. ¿Qué logros o aspectos positivos puede destacar?}

Comparto la conclusión del reconocido sociólogo urbano Pablo Vega Centeno, quien destacó que, en Lima, el Centro Histórico dejó de ser el único gran centro de la ciudad hacia 1980, dando paso al surgimiento de concentraciones importantes, como Miraflores, pero sin dejar de ocupar la gran área central de la ciudad. Así, a partir del siglo xxı, destaca la expansión de nuevos conglomerados de desarrollo metropolitanos en las grandes zonas urbanas, denominadas Lima Norte, Lima Este, Lima Sur o Callao.

Igualmente, son relevantes las iniciativas independientes desde la ciudadanía para la preservación del patrimonio y para reclamar la ciudad como propia. Muchos barrios están creando, de manera organizada y en conjunción con sus autoridades, grupos y asociaciones para trabajar por el cuidado de su entorno y por el desarrollo cultural y humano de los vecinos.

Al respecto, en la comuna miraflorina estamos trabajando, desde el 2011, en la transformación del paisaje urbano de Miraflores, con el objetivo de convertirlo en un distrito con una nueva forma de usar y disfrutar sus calles, como ocurre en las grandes urbes del mundo, y promover de esta forma la recuperación de espacios públicos.

\section{4. ¿Qué elementos históricos y culturales considera que deberían revalorarse?}

La recuperación del Centro Histórico, nombrado Patrimonio Cultural de la Humanidad, debería ser uno de los principales retos que la gestión municipal metropolitana tendría que plantearse. En las últimas décadas, han existido planes para la recuperación del Centro Histórico, pero estos no logran el éxito esperado debido a que no llegan a ser ejecutados en su totalidad, principalmente por falta de continuidad en la visión de los alcaldes.

En el Centro Histórico encontramos casonas de patrimonio monumental en zonas abandonadas, en mal estado, en desuso y con problemas de tugurización; lo cual desmerece y disminuye significativamente el valor cultural de la edificación y el del suelo. Algunas de las intervenciones que se ejecutaron en el Centro Histórico han estado orientadas a impulsar y renovar circuitos turísticos, dejando de lado la mejora de los servicios para la población que habita en esta zona.

Las intervenciones que se planteen para la recuperación del Centro Histórico deben estar orientadas a mejorar la calidad de vida de los vecinos, complementadas con servicios y mejoras en el uso de las edificaciones, e incentivos para el desarrollo de actividades culturales y educativas que, al ser desarrolladas, permitan dinamizar la zona.

En general, revalorizar el patrimonio cultural, material e inmaterial, integrarlos a los procesos de desarrollo urbano, como se viene haciendo, por ejemplo, con la Huaca Pucllana en Miraflores, donde se ha logrado con éxito articular esfuerzos entre el gobierno local y la empresa privada para generar un círculo virtuoso donde el patrimonio se convierte en un regenerador urbano que otorga valor a los predios ubicados en sus áreas de influencia, así como en un foco de atracción turística y un espacio cultural de acceso público que integra a la comunidad.

Esta experiencia ha posibilitado la ejecución de un programa de investigación y conservación permanente, que se complementa con actividades de promoción turística y cultural. Entre otros logros, el proyecto arqueológico ha conseguido la conservación del $70 \%$ del complejo y más de 120 mil visitas en el 2016. Cuenta con una sala de exhibición arqueológica y una sala inclusiva para personas con discapacidad visual. También, tiene un programa de visitas guiadas que se realizan diariamente en cinco idiomas (inglés, francés, italiano, portugués y japonés) y uno de 
visitas nocturnas: "Pucllana abre de noche", lo cual incrementa las visitas y los recursos para el complejo. Recientemente, esta iniciativa ha sido reconocida con el Premio Interamericano a la Innovación para la Gestión Pública Efectiva 2016, otorgado por la Organización de los Estados Americanos (OEA).

Asimismo, desde el municipio miraflorino, venimos mostrando propuestas en los espacios públicos con la finalidad de democratizar el acceso al arte, la historia y la cultura viva; y promoviendo en el transeúnte nuevas formas de mirar y entender las calles. De esta manera, se aprovechará el alto tránsito peatonal del distrito para fomentar el intercambio cultural y la creación de ciudadanía desde el entorno urbano, lo que incentivará a compartir nuevas visiones y posibilidades de la ciudad. Dos de las propuestas más recientes fueron: "Galería abierta", que ofrece exposiciones de arte en calles miraflorinas, y "Miraflores QR Tour", que propone una ruta turística-cultural que incluye monumentos y obras artísticas en espacios públicos, a través de códigos QR.

\section{En la perspectiva del bicentenario, ¿qué retos tiene Lima con relación a su pasado histórico y cultural?}

Uno de los principales retos es alcanzar la sostenibilidad urbana en el país, lo cual plantea la necesidad de disponer a futuro de un sistema integrado de ciudades y centros urbanos, alimentados siempre por formas de convivencia y de vida amparadas en una sólida educación y ética.

La autoridad municipal debe recuperar el liderazgo que le permita conducir un crecimiento planificado de la metrópoli, con una atención especial a las poblaciones más vulnerables, y velar por que no exista un urbanismo de la pobreza basado en el tráfico del suelo e invasiones.

Las ciudades de Lima y el Callao, según los estudios del Plan Metropolitano de Desarrollo Urbano (PLAM) 2035, contarán con nuevos centros de desarrollo que las convertirán en el motor dinamizador de las ciudades del país, con proyección al mundo, principalmente sobre la cuenca del Pacífico. Por ello, los acuerdos internacionales, como la Alianza del Pacífico, Mercado Común del Sur (Mercosur) y, recientemente, el Mercado Integrado Latinoamericano (MILA) - que involucra a las ciudades de México, Bogotá, Lima y Santiago de Chile-generan la oportunidad de desarrollar y planificar mejoras en las ciudades.

\section{En ese sentido, ¿qué importancia tiene la universidad respecto al desarrollo de la vida urbana y cultural?}

La formación del futuro residente de Lima se llevará a cabo en la universidad y, por ello, es importante su participación en el desarrollo urbano y cultural de la ciudad. Es necesario que desde las universidades se "repiensen" las ciudades y se tome conciencia de que la formación de la juventud debe estar dirigida a darle sostenibilidad a las urbes y al país, actualizando y modernizando la enseñanza para que esté en condiciones de enfrentar los nuevos retos y obtener respuestas acordes a la actual realidad y la venidera.

De igual modo, es significativa la formación de recursos humanos especializados, preparados para concordar y trabajar conjuntamente con la amplia presencia empresarial en el país. De ahí la importancia de generar alianzas entre los centros de educación superior, las municipalidades distritales y la de Lima, que permitirán promover la participación de dichos centros en los proyectos urbanos de la ciudad. 


\title{
José de la Puente Brunke
}

\author{
Doctor en Historia por la Universidad de Sevilla, España. Profesor principal y decano de la Facultad \\ de Letras y Ciencias Humanas de la Pontificia Universidad Católica del Perú.
}

\section{Tomando en cuenta el pasado histórico y cultural de Lima, ¿cuáles han sido los principales cambios que usted observa actualmente en la ciudad?}

En primer lugar, habría que señalar que Lima ya existía antes del 18 de enero de 1535 . Es decir, en estas tierras había una serie de asentamientos prehispánicos, de cuya existencia sigue habiendo testimonios arqueológicos hasta hoy. Esa es la Lima milenaria, de la cual estamos tomando conciencia cada vez más. La Lima criolla es la que nace con la fundación española: una ciudad que conservó dimensiones bastante parecidas desde el siglo XVI hasta la segunda mitad del siglo XIX, cuando se produce la demolición de la muralla edificada dos siglos antes. El siglo xx —particularmente, en su segunda mitad - fue testigo del gran crecimiento demográfico de Lima, que es el cambio más notorio que podemos mencionar. Dicho de otro modo, hasta inicios del siglo $x x$, Lima tenía una magnitud poblacional no muy distinta de la de los siglos anteriores, y las dimensiones físicas de la ciudad eran también parecidas.

2. ¿Cuáles considera que son los problemas más resaltantes de los cambios señalados?

El crecimiento físico y demográfico de la ciudad ha supuesto un conjunto de problemas que padecemos cada vez más. Quizá el tráfico es el que genera más complicaciones, debido al pésimo transporte público. Considero que el problema del tráfico no se soluciona con ampliaciones de pistas ni con pasos a desnivel. La solución está en la mejora del transporte público. Si eso ocurre, resultará más eficiente movilizarse por ese medio, con lo cual habrá menos vehículos particulares en las calles.

\section{3. ¿Qué logros o aspectos positivos puede destacar?}

El aspecto positivo más resaltante es el hecho de que hoy en día Lima ya no es más una ciudad criolla. Es decir, hasta el primer tercio del siglo $\mathrm{xx}$, Lima era una urbe con una población fundamentalmente costeña. Hoy es una ciudad en la que se manifiesta la complejidad y la riqueza del Perú. Podríamos decir que Lima es una síntesis del Perú. Por ejemplo, podemos encontrar en nuestra ciudad las tradicionales fiestas criollas, pero también las más importantes celebraciones andinas y de otras regiones del país. Esto es muy positivo, ya que hoy en día Lima refleja, como nunca antes, la complejidad y las riquezas del Perú.

\section{4. ¿Qué elementos del pasado histórico y cultural de Lima deberían revalorarse?}

Deberíamos revalorar tanto el pasado milenario de nuestra ciudad como el pasado de la Lima española y criolla. Además, la revaloración y conservación de los diversos monumentos históricos, y de tantos rincones tradicionales de Lima, debería traer consigo beneficios económicos. Junto con esa revaloración, debemos poner de relieve lo que señalé anteriormente: Lima es una síntesis del Perú.

5. En la perspectiva del bicentenario, ¿qué retos tiene Lima y su gente con relación al tema del pasado histórico y cultural?

Esa riqueza que encierra Lima, en la medida en que hoy es un reflejo de la complejidad y variedad de lo que es el Perú, es un factor que debemos valorar. El Perú del Bicentenario es un país rico, variado y muy complejo. Esa complejidad supone una serie de problemas, pero a la vez constituye una gran riqueza. Los peruanos del Bicentenario debemos estar orgullosos de nuestro pasado y ser conscientes de que nuestra riqueza histórica y cultural debe ser la base de un futuro promisorio.

\section{En ese sentido, ¿qué importancia tiene la universidad respecto de la ciudad y su pasado histórico y cultural?}

Pienso que en la formación que se brinda en el ámbito universitario debe estar siempre presente la base humanística. Si eso es así, habrá mayores posibilidades de que nuestra sociedad valore sus tradiciones y su pasado histórico. 


\title{
Pedro Pablo Alayza
}

\author{
Licenciado en Arqueología e Historia del Arte por la Universidad Libre de Bruselas, Bélgica. \\ Director del Museo Pedro de Osma.
}

\section{Tomando en cuenta el patrimonio monumental de Lima, ¿cuáles han sido los principales cambios que usted observa actualmente en la ciudad?}

Lima es una ciudad eminentemente patrimonial, pues cuenta con una muy antigua historia de ocupación humana: los yacimientos más antiguos, como los de Ancón, previos a las construcciones monumentales de los templos en $U$ de Garagay y muchos otros, hasta el gran Templo del Sol de Pachacamac. A este largo período del esplendor prehispánico debemos añadir aquello que sucede durante la época virreinal y, luego, los últimos doscientos años de República. Durante estos pocos miles de años de intensa actividad humana y, por tanto, cultural es muy poco lo que se ha hecho proporcionalmente. Es solo a partir de la década de los treinta y cuarenta del siglo pasado que el interés por el patrimonio tomó forma, desgraciadamente siempre de manera discontinua y errática. Hay que señalar que el patrimonio virreinal y republicano no han tenido mejor suerte.

A falta de políticas públicas sostenidas o coherentes, solo debido a algunas iniciativas, con nombre propio y en momentos muy peculiares, el patrimonio ha sido atendido: Tello y el Templo de Mamaconas, en Pachacamac, el Museo de Sitio de Puruchuco, por Jiménez Borja, y El Paraíso por Engel, por citar algunos ejemplos del siglo pasado. Este temprano y efímero interés por la Lima precolombina ha tomado nuevos aires e intereses de diversa magnitud y suerte en las últimas décadas; lo que, me parece, será determinante para lo que nos espera como ciudad, desde un punto de vista patrimonial.

En la actualidad se ha producido un fenómeno muy distinto en los que la ciudadanía ha tomado el protagonismo. La recuperación de las huacas de las tradicionales zonas urbanas de la ciudad; como la de Pucllana en Miraflores, donde el municipio ha jugado un rol determinante al compartir la administración del monumento con el INC; lo mismo ha sucedido en Magdalena con la Huaca Huantile y, más recientemente, con la Huaca Palomino en la avenida Venezuela, de El Cercado. Mención especial merecen las pirámides de Mateo
Salado, al borde de la Plaza de La Bandera y bajo la tutela del actual Ministerio de Cultura; ahí, desde hace casi una década, se ha sostenido un programa de investigación arqueológica en el que, además del evidente interés científico, se ha logrado una ejemplar relación con los vecinos del sitio y han hecho de este un proyecto sostenible.

Un último modelo de recuperación del patrimonio se ha dado en la nueva Lima, en la que los vecinos han sido los actores directos de este fenómeno. Se trata de las poblaciones desplazadas hacia la ciudad que han hecho suyo algunos sitios arqueológicos al convertirlos en un lugar de encuentro ciudadano y un motivo de identidad y enraizamiento locales. La iniciativa de protección de los sitios arqueológicos por el Colectivo Colli en Comas, o la de los vecinos de la Huaca Fortaleza de Campoy en San Juan de Lurigancho -en ambos casos liderados por los profesores de las escuelas vecinas a los monumentos-, son muestras elocuentes del genuino interés por este patrimonio olvidado...

\section{2. ¿Cuáles considera que son los problemas más resal- tantes de los cambios señalados?}

Es evidente que los problemas del patrimonio dependen en gran medida de las autoridades, su deber se debe centrar en establecer políticas públicas en las que articule el patrimonio con la ciudadanía.

\section{3. ¿Qué logros o aspectos positivos puede destacar?}

Como hemos señalado líneas arriba, tenemos muy buenos ejemplos de los cuales debemos tomar las lecciones correctas. Toda iniciativa relacionada con este inmenso patrimonio - solo en Lima existen más de 400 sitios arqueológicos, y los centros históricos de Lima, el Rímac y Barranco- debe ser entendida como propuesta destinada a revalorizarlo, tanto desde la perspectiva histórica como de la mejora de la calidad de vida de los vecinos. No debemos olvidar que los pocos espacios públicos de la ciudad suelen ser los vestigios precolombinos; por ello, sus posibilidades para el logro de lo señalado es capital. 
4. ¿Qué elementos del patrimonio monumental de Lima deberían revalorarse?

Nos hemos referido al patrimonio precolombino, pero la tarea debe sostenerse también en la herencia virreinal y republicana. El Patronato de Lima hizo posible la declaratoria de la ciudad como Patrimonio de la Humanidad hace casi treinta años; sin embargo, es poco lo que se ha hecho en este tiempo. Es urgente retomar el espíritu original y recuperar de modo sostenido la tres veces coronada ciudad de Lima. Un muy buen ejemplo actual es el Patronato del Rímac, que ha logrado establecer un programa coherente que involucra a las instituciones privadas con las públicas, en alianza con los vecinos.

5. En la perspectiva del bicentenario, ¿qué retos tiene Lima y su gente con relación al tema del patrimonio histórico y cultura?

El Bicentenario debe entenderse como un momento privilegiado, en el que el país debe intentar una nueva mirada. Tomar conciencia de qué país queremos y plantear políticas para los próximos años, aprender de las vicisitudes republicanas, recoger las lecciones necesarias para plantear perspectivas audaces y creativas.
Los retos son enormes, algunas experiencias han sido muy duras, como los recientes años de violencia que vivió el país. Es imperativo intentar nuevas maneras de convivencia que son necesariamente culturales. Mucho se ha escrito y se ha hecho desde el campo de la memoria para intentar una lectura de nuestra realidad. La exhibición Yuyanapaq y el Lugar de la Memoria son dos hitos en la ciudad que deben entenderse como proyectos culturales indispensables para reflexionar sobre lo vivido, así como sobre nuestras posibilidades futuras.

El patrimonio cultural nos ofrece, como hemos visto, posibilidades enormes para el encuentro ciudadano.

6. En ese sentido, ¿qué importancia tiene la universidad respecto de la ciudad y su patrimonio histórico y cultural?

La universidad es el lugar de la discusión y la reflexión, es el espacio desde el cual se deben plantear las rutas tanto teóricas como prácticas para el futuro de las sociedades. Desde las distintas disciplinas, es indispensable revisar los planes nacionales para los próximos años, pues son muchas las iniciativas que se han dado desde la universidad para establecer una mejor relación con el patrimonio. La oportunidad del bicentenario debe ser aprovechada. 


\section{Elena Benavides}

Fundadora y directora de Casa Cor Perú, la mayor y más completa muestra de arquitectura, diseño de interiores y paisajismo de las Américas.

\section{Tomando en cuenta la fisonomía histórica de Lima, ¿cuáles han sido los principales cambios que usted observa actualmente en la ciudad?}

Lamentablemente los cambios que podemos observar no han sido positivos. Hay demasiada improvisación y no se ha tenido ninguna visión de futuro, ya que se han hecho cambios sin planificación, sin criterio urbanístico y cultural. Estos cambios negativos ocurren desde hace mucho. Recuerdo que cuando era niña escuchaba pasar cerca a mi casa en Monterrico el tren que venía de Lurín con dirección a la estación de Desamparados y luego empalmaba con el tren que iba hasta Ancón. Hoy en día este tren no existe, no tengo que entrar en mayores explicaciones para que se entienda lo que hemos perdido.

\section{2. ¿Cuáles considera que son los problemas más resal- tantes de los cambios señalados?}

La congestión vehicular que tenemos que soportar todos los días para hacer cualquier diligencia en la ciudad es casi intolerable. El problema es que no hay propuestas de corto plazo para solucionar esta situación y algunas acciones son incompletas o inútiles. Es responsabilidad del Estado y sus diferentes instancias asegurar la calidad de vida de los ciudadanos.

\section{3. ¿Qué logros o aspectos positivos puede destacar?}

A través de Casa Cor, mi socia Verónica Torres de Haaker y yo estamos orgullosas de haber recuperado para Lima quince monumentos históricos y arquitectónicos, que en muchos de los casos estaban a punto de colapsar. Cabe resaltar que estos proyectos han tenido éxito gracias a la colaboración de las municipalidades de los distintos distritos donde se ha desarrollado el evento y del Ministerio de Cultura, entidades que han sabido aprovechar la colaboración de la empresa privada para la recuperación de estos inmuebles.

4. ¿Qué elementos históricos de la fisonomía urbana deberían revalorarse?

Nosotras creemos que las plazas y parques son espacios públicos que deberían desarrollarse y atenderse mejor, ya que hay muchos ejemplos de lo que no se debe hacer. Es necesario diseñar y ejecutar propuestas profesionales que articulen los elementos tradicionales y modernos, y que contribuyan a dinamizar la vida social y cultural de la ciudad.

\section{En la perspectiva del bicentenario, ¿qué retos tiene Lima y su gente?}

El principal reto de hoy creo que es el transporte. Hace falta un plan de desarrollo vial que favorezca la movilidad de las personas; es necesario mejorar su calidad de vida, ya que de este modo se podrán generar otras dinámicas que contribuyan a una mayor conciencia y responsabilidad de los espacios públicos y sus elementos patrimoniales. Así, entraremos al bicentenario con ciudadanos y gobiernos que valoren y respeten los elementos patrimoniales del entorno.

\section{En ese sentido, ¿qué importancia tiene la universidad respecto la ciudad y su desarrollo?}

Muchísima. Hace falta enseñar urbanismo y planeamiento urbano, teniendo en cuenta los ejemplos directos de grandes ciudades en las que las grandes avenidas se construyeron con una visión de futuro, hace más de cien años. Lima debe encontrar la forma de mejorar su desarrollo urbanístico, buscando conjugar su patrimonio histórico-cultural con las posibilidades de desarrollo que tiene. 


\title{
José Quezada Macchiavello
}

\author{
Director musical en Schola Cantorum Perú. Investigador en musicología del barroco peruano, \\ compositor, docente universitario, escritor y promotor social y cultural.
}

\section{Tomando en cuenta la historia cultural/musical de Lima, ¿cuáles han sido los principales cambios que usted observa actualmente en la ciudad?}

Un primer cambio significativo es la ampliación del público y la diversificación de las preferencias. Empieza a existir un público con oídos abiertos, capaz de acudir a conciertos de distintas expresiones. La música clásica, quizá gracias a la web, empieza como en muchos países a ser apreciada en distintos niveles socioeconómicos y sin que esto signifique la exclusión de otras preferencias musicales. Se puede apreciar el rock pesado y a Beethoven, por ejemplo, y esto ya sucede en Lima de manera extendida.

Creo que, poco a poco, irán apareciendo distintos centros de cultivo en diferentes lugares de la ciudad. La refacción del Teatro Municipal y la inauguración del Gran Teatro Nacional es un gran hito. Si se suma el Teatro de la UNI (Universidad Nacional de Ingeniería), el de la Unifé (Universidad Femenina del Sagrado Corazón) y el ZUM (Zona de Usos Múltiples) de la Universidad de Lima, así como el Auditorio Santa Úrsula, se cuenta ya al menos con seis espacios para conciertos. No obstante, Lima no cuenta aún con un teatro en Lima Sur, y en general con un teatro que tenga la dimensión que la ciudad requiere -al menos para 2500 espectadores- para ópera, conciertos y musicales. El Gran Teatro Nacional es un avance, pero no es el Teresa Carreño de Caracas o el Colón de Buenos Aires. Espero que, para el 2021, 2500 a 3000 personas puedan asistir en Lima a un verdadero gran teatro y que la ciudad cuente con no menos de diez espacios en distintos lugares.

\section{2. ¿Cuáles considera que son los problemas más resal- tantes de los cambios señalados?}

He señalado que la falta de espacios de dimensión apropiada para la difusión musical. Añado que el caos vehicular - que no creo que sea un problema que se vaya a resolver muy fácilmente- hace imprescindible que la oferta cultural se dé en distintas zonas de la ciudad. Por otro lado, el Estado sigue siendo el gran protagonista de la gestión cultural, que muchas veces compite deslealmente (dumping) con los privados. No se cuenta con estímulos tributarios para que la empresa privada otorgue recursos a la cultura. Hay que lograr que los empresarios asuman que la cultura es un asunto que les compete. No deben ser exclusivamente benefactores, sino gestores directamente comprometidos.

\section{3. ¿Qué logros o aspectos positivos puede destacar?}

Sin duda, que no estamos "en cero", como lo he señalado en la respuesta a la pregunta uno.

\section{4. ¿Qué elementos de la historia cultural/musical de} Lima deberían revalorarse?

La herencia barroca, por ejemplo. El barroco musica debería convertirse en un elemento de atractivo para los turistas. Yo estoy en eso. Creo que escuchar música barroca, no solo peruana, en iglesias como El Sagrario, La Virgen de la O, o en la Sala Capitular de Santo Domingo o la Sacristía de San Francisco, es un privilegio.

\section{En la perspectiva del bicentenario, ¿qué retos tiene Lima y su gente con relación al tema de la cultura/música?}

Ser el centro cultural y musical del Pacífico, y lograr que la música sea un instrumento de inclusión social. Hay varias iniciativas valiosas que, de alguna manera, contribuyen a democratizar el acceso a la música, pero no se trata solamente de llenar el tiempo libre de los niños y jóvenes para que no entren en el mundo de la delincuencia, sino en descubrir y alentar a los talentos. Aun cuando aparece un gran talento, es común escuchar que hay que sacarlo pronto del país. Esto es lamentable. No ocurre así en México, en Brasil o en Venezuela (a propósito, espero con real preocupación que Venezuela no pierda el extraordinario nivel musical que logró en cuarenta años). Creo, sin embargo, que el reto debe ser para la sociedad civil, las universidades, las instituciones: lo menos de Estado que sea necesario y lo más de iniciativa privada que sea posible.

6. En ese sentido, ¿qué importancia tiene la universidad respecto de la ciudad y su desarrollo cultural/musical?

Tienen un rol fundamental. La universidad, mejor dicho, todas las universidades deberían comprometerse activamente y de manera seria en la promoción de la cultura musical, creando alianzas estratégicas con las organizaciones que se ocupan de este tema y que cuentan con técnicos y equipos apropiados. 


\title{
César Guadalupe Mendizábal
}

\author{
Doctor en Educación por la Universidad de Sussex, Reino Unido. Profesor-investigador \\ en la Universidad del Pacífico y presidente del Consejo Nacional de Educación (CNE).
}

\section{Tomando en cuenta el pasado educativo y cultural de Lima, ¿cuáles han sido los principales cambios que usted observa actualmente?}

Con relación al sistema educativo, me parece que lo más importante se vincula a dos problemas: cambios demográficos y cambios asociados a la mejora (limitada) de los niveles de vida de la población. Ambos, asociadas a una imagen negativa de la educación pública, han llevado a una ran reducción de la matrícula (en general), a que esta reducción se concentre exclusivamente en los colegios estatales y a que se dé un traslado de matrícula hacia el sector no estatal.

Así, la educación estatal se ha reducido en tamaño, y la no estatal ha crecido y se ha vuelvo mucho más heterogénea que en el pasado. Hoy, la escuela privada no es sinónimo de escuela de clase media o media-alta, sino que incluye a este segmento y a sectores que hacen un gran esfuerzo para escapar de la educación estatal, aunque este esfuerzo solo les permite acceder a un servicio educativo tanto o más mediocre que el ofrecido por el Estado.

Ahora bien, la educación no es solo el sistema educativo, sino que es el resultado de la acción intencional o no intencional de muchos actores. Los debates en redes sociales, la forma como la prensa trata los problemas públicos, la fragilidad institucional, la precariedad del sistema de representación democrática (y de los representantes), los medios de comunicación, y el actuar cotidiano de las personas, son agentes y espacios que podrían llamarse "antieducativos". De hecho, la parte mayor del problema educativo peruano no está solo en los limitados resultados en lectura o matemáticas, sino también en las dificultades con el pensamiento abstracto - sin el cual no se puede reconocer al otro como igual, salvo que sea muy próximo- y con las pautas de interacción, respeto y trato entre las personas, y entre todos y el entorno legal e institucional.

\section{2. ¿Cuáles considera que son los problemas más resal- tantes de los cambios señalados?}

Lo anterior me parece que ha tendido a reforzar prejuicios y relaciones de conflicto y desprecio entre las personas, así como ha tornado muy difícil construir una sociedad basada en el imperio de la ley.

\section{3. ¿Qué logros o aspectos positivos puede destacar?}

El sistema educativo ha mejorado en los últimos veinte años, como lo atestigua toda la evidencia sobre logros de aprendizajes; también, la continuidad de algunas políticas educativas. Sin embargo, no son mejoras que nos pongan en el nivel que quisiéramos, tanto por restricciones propias del sistema educativo como por tener que ir a contracorriente de otros procesos sociales más complejos.

\section{4. ¿Qué elementos del pasado educativo y cultural de Lima deberían revalorarse?}

Lima pre-1960 era una sociedad que valoraba la escuela pública y en la que las personas buscaban enviar a sus hijos a esta, salvo casos limitados en los que se buscaba algún tipo específico de educación (religiosa, una lengua internacional, etcétera) y, seguramente, también había un lamentable componente de segregación. Hoy, la segregación parece ser el criterio central con el que los limeños buscan escuela para sus hijos.

\section{En la perspectiva del bicentenario, ¿qué retos tiene Lima con relación a la educación y la cultura?}

Los retos de Lima no son muy distintos a los que afectan al país en su conjunto, excepto en un aspecto: el centralismo limeño y los problemas de segregación, que se hacen más patentes en una ciudad del tamaño de Lima.

\section{En ese sentido, ¿qué importancia tiene la universidad respecto de la ciudad y el desarrollo de la educación y la cultura?}

La universidad (no toda ella, pero al menos la que se entronca en una perspectiva humanista) es un espacio desde el que se puede y debe afirmar la necesidad de construir una educación para el desarrollo de la ciudadanía y la construcción de una república. En ese sentido, la universidad puede emplear su prestigio y sus contribuciones intelectuales para entender los problemas y para convocar el necesario esfuerzo nacional con la finalidad de construir una mejor vida para todos. En particular, la universidad debería ejercer toda su influencia para contrarrestar prácticas de arrogancia y desprecio por el otro, que hoy incluye el desprecio por lo educado. 


\section{David Mutal Vermeulen}

Arquitecto y urbanista por la Universidad Ricardo Palma, Perú. Obtuvo el primer premio en la categoría Patrimonio Histórico por la renovación de la Estación de Desamparados, así como otras distinciones.

\section{Tomando en cuenta el patrimonio arquitectónico de Lima, ¿cuáles han sido los principales cambios que usted observa actualmente en la ciudad?}

Nuestro rol con relación al patrimonio arquitectónico de la ciudad se centra en la intervención sobre predios existentes de origen republicano, tanto en el Centro Histórico como en zonas monumentales; Barranco o Chorrillos, por ejemplo. En este campo, como arquitecto que se inserta en estos contextos, en los últimos años he visto un mayor interés de parte de clientes o inversionistas por estos espacios que, de alguna manera, son considerados como más auténticos y relacionados con la identidad de la ciudad. Este interés es de diversa índole; desarrollos inmobiliarios, hoteles o casas privadas buscan este tipo de ambientes. Sin embargo, hay mucho por hacer todavía para establecer políticas más concretas para la salvaguarda de estos bienes patrimoniales.

2. ¿Cuáles considera que son los problemas más resaltantes de los cambios señalados?

Los problemas más resaltantes de este impulso tienen que ver con la normativa vigente y la falta de reglas claras, donde muchas veces se sobreponen las decisiones municipales a las directivas del Ministerio de Cultura, en el caso de obras nuevas en zonas monumentales, así como la falta de claridad en la manera cómo se juzgan los proyectos de adecuación de edificios declarados como monumentos o de valor monumental.

Estos procesos tienden a ser mucho más largos que los procesos de permisos en obras fuera de estos ámbitos, y frenan la iniciativa de los inversionistas o inclusive particulares, para los cuales el tiempo del retorno de la inversión -como es lógico- es una variable financiera importante.

\section{3. ¿Qué logros o aspectos positivos puede destacar?}

Se dieron algunas normas en los últimos años que van en la dirección de agilizar estos procesos, aunque me parece que todavía son muy insuficientes. En general, se entiende que, si se flexibilizan los procesos, eso daría pie a que más proyectos de dudosa calidad pasen la valla y haya más destrucción del patrimonio, pero eso ya pasa en la actualidad porque la inflexibilidad de las normas promueve la informalidad en ámbitos más lejanos, que de alguna manera no son tan fiscalizables. Me parece que al Ministerio de Cultura no solo le falta aplicar de una manera reglamentaria el sentido común -lo que, entiendo, no es fácil一, sino también tener un rol promotor del valor del rescate del patrimonio. Hoy en día, desde nuestro punto de vista, es solo un ente regulador que dice sí o no; pero no dice: "¡miren qué es lo que podemos hacer!" Los arquitectos -y me incluyo-, a pesar de que hemos ganado premios en estos temas, somos mirados con demasiada suspicacia y siempre bajo un solo criterio, que a veces termina siendo un sesgo casi ideológico de cómo se debe intervenir el patrimonio cuando hay mucha discusión al respecto a nivel nacional e internacional.

\section{4. ¿Qué elementos del patrimonio arquitectónico de Lima deberían revalorarse?}

Más que definir un área específica, creo que debería haber un tratamiento diferenciado y estratégico de cómo se debe revalorizar las diversas zonas patrimoniales de la ciudad. Es decir, que las áreas de protección no deberían ser tratadas de manera uniforme. Me parece que, según su ubicación, cada predio monumental debería estar sujeto a mayor o menor flexibilidad de intervención para fomentar la inversión en zonas dilapidadas y menos atractivas, donde las casonas se caen por falta de interés. Creo que los espacios monumentales son en sí mismos atractivos y tienen un potencial enorme, pero eso solo es posible si les puede insuflar vida con normativas más específicas, flexibles y coherentes, relacionadas con la especificada de cada cuadra, barrio o zona. 
5. En la perspectiva del bicentenario, ¿qué retos tiene Lima y su gente en relación con el tema del patrimonio arquitectónico?

Lima tiene muchísimo patrimonio para poner en valor y potenciar. Creo que no nos damos cuenta y lo tomamos como algo dado, que está ahí; que nos quedamos esperando que los inmuebles o las casonas se caigan porque no se pudo hacer nada, o a que inversionistas ideales y altruistas transformen cada casona en una casa, un museo o un hotel, usos que pueden ser ideales en el contexto del rescate del patrimonio como objeto arquitectónico, pero que no son económicamente viables en la totalidad de las áreas que debemos proteger.
6. En ese sentido, ¿qué importancia tiene la universidad respecto de la ciudad y su patrimonio arquitectónico?

Tiene la gran responsabilidad de inculcar estos valores de rescate con criterio amplio entre los alumnos, no solo de arquitectura. Los centros históricos son sistemas dinámicos que requieren una visión más amplia y multidisciplinar, que vaya más allá del aspecto físico de la conservación en sí. El espacio universitario, en ese sentido, es el laboratorio ideal para llevar a cabo esta visión más amplia. 


\section{Enrique Bonilla Di Tolla}

Arquitecto y urbanista por la Universidad Ricardo Palma, Perú. Director de la Carrera de Arquitectura de la Universidad de Lima, Perú.

\section{Tomando en cuenta el patrimonio arquitectónico de Lima, ¿Cuáles han sido los principales cambios que usted observa actualmente en la ciudad?}

Sobre la conservación del patrimonio hay, por épocas, tendencias variadas. Desde hace algunos años, hay una fuerte tendencia a la recuperación del patrimonio prehispánico, que por años estuvo olvidado. Esto empezó en los años ochenta del siglo pasado y hoy hay un cuidado muy grande por las huacas, y se habla incluso de la recuperación de los viejos canales — mal llamados ríos - que irrigaban el valle del Rímac. Se observa también un decaimiento de la conservación del patrimonio colonial y republicano, que resulta poco interesante e incluso está lentamente desapareciendo. Barranco, donde por años se trató de conservar el espíritu decimonónico y republicano, hoy es el principal espacio de lo que los urbanistas llaman "gentrificación"; se está sustituyendo la población original por otra que viene a ocupar pequeños departamentos en nuevos edificios. El patrimonio que no tiene ninguna protección es el denominado patrimonio moderno, que corresponde al siglo xx. Ese está desapareciendo por culpa del boom inmobiliario de los últimos años. Tal vez en poco tiempo no quede ni rastro de la ciudad del siglo $x x$, de la que no se tiene inventario ni medidas de protección.

\section{2. ¿Cuáles considera que son los problemas más resal- tantes de los cambios señalados?}

Yo, que tengo algunos años, recuerdo que en los años setenta del siglo pasado se hacía motocrós en la Huaca Juliana y hoy, gracias a la buena gestión del Municipio de Miraflores, es un espacio que se ha recuperado y se ha puesto en valor. La propia declaratoria de un sector importante del Centro Histórico de Lima como Patrimonio de la Humanidad por Unesco, en 1991, fue el punto de inflexión para iniciar un proceso de recuperación de la vieja Lima, aunque en los últimos años ha perdido un poco de fuerza, pero no se ha descuidado. Otros centros históricos, como los de El Callao, Barranco y Magdalena (Pueblo Libre) —en este último he participado directamente-, han sido objeto de recuperación de espacios públicos y de algunos inmuebles. También, es importante señalar que se va creando conciencia del valor del patrimonio, incluso desde el punto de vista comercial. El trabajo de la empresa de capital español Art Express, comprando y recuperando inmuebles en el Centro Histórico de Lima, es importante. Esta misma empresa ha anunciado la reconstrucción de uno de los ocho edificios que conforman la plaza 2 de Mayo, que se incendió hace varios años y que parecía que se perdería definitivamente. Esperemos que continúe con el resto de edificios. Es importante también que el patrimonio se rentabilice y no se vea como un lastre, como sucede en muchos lugares.

\section{3. ¿Qué logros o aspectos positivos puede destacar?}

Si se quiere recuperar el patrimonio arquitectónico, hay primero que crear la conciencia del valor de este. Para la mayor parte de los actuales limeños, que tienen básicamente un origen migrante, la ciudad les dice muy poco. Por lo general, sus padres no son de aquí y, por supuesto, mucho menos sus abuelos. La conciencia del patrimonio empieza, como todo, en la casa, en la familia. Lima está hoy llena de manifestaciones culturales traídas por los migrantes, que son básicamente un patrimonio inmaterial. El patrimonio inmaterial de Lima prácticamente ha desaparecido. Cada día se escucha menos música criolla y menos valses. En una década más, tal vez, desaparezca del todo.

En el caso del patrimonio material, este tiende a la permanencia, pero para conservarlo hay que procurar que la población lo valorice. Creo que, en ese aspecto, algo hemos avanzado, pero hay que seguir insistiendo.

\section{4. ¿Qué elementos del patrimonio arquitectónico de Lima deberían revalorarse?}

Lima es una ciudad compleja y tiene patrimonio valioso desde la época prehispánica hasta nuestros días. Toda ella merece atención. Si cada uno de los 43 distritos de 
Lima identificara su patrimonio arqueológico, arquitectónico y urbano, y lo conservara, podría ser muy interesante. La municipalización de la conservación del patrimonio abundaría en la conservación de un acervo cultural, que, dado que pertenece a la nación, debe ser responsabilidad del Estado en su expresión más pequeña, que son las municipalidades.

\section{En la perspectiva del bicentenario, ¿qué retos tiene} Lima y su gente con relación al tema del patrimonio arquitectónico?

Sería muy interesante, por ejemplo, generar una política de recuperación de centros históricos para el bicentenario. Se podría establecer un plan de conservación de ciertas ciudades con patrimonio valioso. Lima, Arequipa, Cusco y Trujillo deberían ser parte de este plan, que también debe incluir a Huamanga (Ayacucho), Moquegua, Cajamarca y Chachapoyas, cuyos centros históricos han sido poco alterados y conservan no solo el trazado urbano, sino el contexto urbano. Para que esto pueda suceder, tendría que generarse una política que involucre a los ministerios de Cultura y Vivienda, así como los gobiernos regionales y locales de estas ciudades.
6. En ese sentido, ¿qué importancia tiene la universidad respecto de la ciudad y su patrimonio arquitectónico?

No puedo hablar por toda la universidad peruana, pero nosotros, en la Universidad de Lima, formamos a nuestros estudiantes con plena conciencia del valor del patrimonio. Uno de los diplomas que entregamos a nuestros egresados que cursan las materias correspondientes es en Conservación del Patrimonio Edificado.

Además, como Carrera de Arquitectura, venimos trabajando arduamente en lograr un reconocimiento del patrimonio del siglo $x x$ o patrimonio moderno que, tal como decía al principio, carece no solo de protección, sino que no está ni siquiera inventariado. Al respecto, hemos hecho varias exposiciones en torno a la obra de importantes arquitectos peruanos y hemos publicado libros sobre la obra de Héctor Velarde, Walter Weberhofer y, recientemente, sobre Mario Bianco. Además, bajo la autoría de Alejandra Acevedo y Michelle Llona, se ha editado recientemente el Catálogo del Movimiento Moderno en el Perú; que, a decir del crítico Luis Lama, es "un proyecto editorial sin precedentes. Más que un catálogo, una regocijante enciclopedia". 